\title{
LINGUISTIC FOUNDATIONS OF COGNITION OF THE PROCESSES OF SOCIAL AND CULTURAL REALITY
}

\section{Oleksandr Zheltoborodov ${ }^{1}$ Nina Petrusenko ${ }^{2}$}

DOI: https://doi.org/10.30525/978-9934-26-021-6-28

\begin{abstract}
A philosophical analysis of the nature of economic processes in the modern intellectual discourse is carried out in line with mosaic civilization transformations and the communication process as a fundamental translation of one language of activity into another. The result of such an operation is the personification of the linguistic reality of the form of socioeconomic life of society, and the methodological basis of this approach is L. Wittgenstein's idea of a natural language as the personification of a form of life, reflecting a stable system of linguistic and non-linguistic activity. The article substantiates the potential of the linguistic approach, which reveals the heuristic possibilities concerning the formation of meaning in the system of socio-economic knowledge. It is noted that the use of any language, including limiting its laws of syntax and vocabulary based on the practices and symbols, are not exhausted by any rules and become linguistic innovations. It is proved that the natural speech is published in the associated objects and situations but in the future it builds a categorical ordered system of values which referents becomes specified primary connection, which, in turn, uniquely combine choice means subjects with perceptive articulations and practical necessity. It was found that any code or an artificial language remains dependent on the existence of a natural language which allows us to determine from the side of the predication conditions the conditions of a person's access to the world. It is shown that the logical construction which are aimed at the relation of predicates and referents, as well as at the transition from sentence to proof, themselves, in turn, are tuned over more fundamental layers of the statement, which include initial statements and validity open for research.
\end{abstract}

\footnotetext{
${ }^{1}$ Candidate of Historical Sciences, Associate Professor, Kharkov State Academy of Physical Culture, Ukraine ${ }^{2}$ Associate Professor, Kharkov State Academy of Physical Culture, Ukraine

(C) Oleksandr Zheltoborodov, Nina Petrusenko
} 


\section{Introduction}

The actual task of the social and humanitarian sciences is to analyze the problematic continuum of their categorical apparatus and to study the theoretical and methodological foundations of the process of forming a modern system of concepts of socio-economic knowledge. For this attempts to investigate the mechanisms of the specifics of the formation of the language of social sciences and the humanities as a universal means of objectifying individual consciousness and cultural tradition in a situation of transformational processes in the modern world become necessary. Language characterizes the ways and principles of thinking of a particular cultural and historical period, largely determining human behavior [1]. Language, terms, words are not things themselves, but how they designate a particular sphere of activity, reveal the meaning and meaning of objects. It is the words that are translated into the subconscious and then into the consciousness, the meaning of things that exists in the mentality of every nation. Taking into account the process of the genesis of socio-economic knowledge in the study, using the meaning of concepts and categories in the historical territory of the people's residence, recognizing words - symbols, words - signs that are carriers of national culture - this is the beginning of understanding the mentality of the people.

We set the task of carrying out a socio-philosophical analysis of the nature of socio-economic processes in modern intellectual discourse in a unified line of civilizational transformations of our time, provided the communication process is a fundamental translation of one language-activity into another. The result of such an operation is the personification of the linguistic reality of the form of socio-economic life of society, where the methodological basis of this approach is L. Wittgenstein's idea of natural language as the personification of «life forms» reflecting a stable system of linguistic and non-linguistic activity. This approach substantiates the analysis of the mechanism of interaction of the systemic nature of material production and world economic processes with the national paradigm of socio-economic knowledge, which ensures the formation of its own mental and semantic field of the people's production activity. It is necessary to explain our understanding of the meaning of the very sphere of linguistic praxeology [2]. The categories of linguistics have a wide semantic load and a voluminous history of their theoretical formation in the world of scientific explanation of 
reality. One of these areas is the division of linguistics into an internal form of functioning which includes its own laws and rules for the improvement of the language and the external interaction of the language with natural and social factors [8]. The result of such external interaction is such spheres of intellectual activity as sociolinguistics, cultural linguistics and semasiology. Sociolinguistics investigates the existence of language in certain social conditions, the range of its issues includes the problems of language and ethnicity, modeling of socially determined linguistic activity. It is necessary to determine the relationship between linguistic and social structures [4] from the point of view of accounting for influence on the social sphere of this or that ethnic group of the socio-economic factor. An important aspect is the development of a special concept of the linguistic reality of national socioeconomic knowledge: «economic knowledge, as a relatively independent branch of worldview research, is formed and developed according to certain rules for each nation starting with the geographical factor and ending with the primordial eschatological ideas. In its turn philosophical science theoretically solves universal human problems of being through the prism of national approaches, thereby directly providing a universal connection between the social sciences and the humanities with knowledge as a whole. Consequently the relevance of studying the modern development of social and humanitarian knowledge requires new methodological approaches to the analysis of the interaction of the objective nature of the functioning of economic processes, directly material production with a peculiar national paradigm of socio-economic knowledge.

\section{Pragmatics and perception of texts of a socio-economic nature}

The basic principles of this paradigm are actually the national-semantic field of socio-economic development, it includes the history of economic experience in the territory of a certain territory, linguistic characteristics and social values of each nation. Although from the standpoint of the postmodern approach to these problems, when the modern mentality is characterized by a total absence of «faith in meaning» because everything is considered a source of semantic certainty from the point of view of M. Foucault, it is necessary to study important spheres of human existence through the prism of linguistic reality. Attention should also be paid to the use of the possibilities of the pragmatics of the text as a «sign formation that fixes the relationship between 
the text and the subjects of textual activity. Traditionally the pragmatics of the text offers consideration of the communicative interests of the reader and observing the fundamental principles of linguistic communication» $[17$, p. 623]. In this aspect it is advisable to analyze the specifics of the perception of texts of a socio-economic nature both in the process of historical development and modern interpretations, when according to J. Baudrillard [5], there is more and more information and less and less meaning. The study of these problems requires to pay research attention to the specifics of the cultural and historical experience of a particular people, the peculiarities of the formation of its economic principles and means of life support, it is necessary to find out the level of economic mentality by analyzing the formation and functioning of the linguistic reality of the historically built architectonics of socio-economic knowledge. The term «mentality» is used when it is necessary to designate something relatively difficult to grasp but at the same time really present in social reality, first of all the conditioning of certain facts of consciousness or behavior of people; when it is necessary to rationally explain certain phenomena of social life, going deeper to a certain level of their foundations. The study of the semiotic space of economic culture, the problems of its historical formation, possible patterns of its development and the prospects for further analysis acquire a special modern meaning. The analysis of the mechanism of mutual influence of the phenomenon of mentality and the process of formation and functioning of the structure as values of socio-economic knowledge becomes a logical continuation of the discursive-analytical study of the national style of socioeconomic knowledge.

The methodology of discourse theory becomes a specific intertwining between postmodern philosophy of language, semiotics, linguistics in its modern versions, sociology of knowledge and cognitive anthropology. Postmodernism penetrates the system of economic scientific knowledge thanks to the non-traditional methodological concept of D. McCloskey [12]. This concept is based on the use of those rhetorical techniques that often become components of the scientific practice of a researcher: methodological pluralism, relativism, etc. In contrast to a clearly defined scientific modernism D. McCloskey [12] opposes the concept of science as a free market of ideas in which competing among themselves, experts trade in «ideal» goods, while the classics of modernity are not rejected. Concerning 
the category of discourse it should be noted the works of E. Laclos and C. Mouffe [11] in which a discourse theory is created on the basis of social constructionism, that is discourse exists as a way of reproducing various social mechanisms and in the works of A. Gramsci, L. Althusser and M. Foucault discourse is viewed as an opportunity to reflect the processes of the social world.

With the further development of the globalization process the specificity of the functioning of local and national cultures is more and more clearly observed, the need to preserve cultural identity is increasingly perceived. «Understanding the essence» of the culture of the economic-production process as the basis for the development of both pre-industrial and post-industrial civilization is carried out in the works of F. Braudel [5], M. Weber [18], K. Marx [13]; T. Parsons [15] and R. Merton [14] create a comprehensive basis of anthropological structural functionalism not only at the level of philosophical analogy but also on specific empirical studies. $\mathrm{L}$. Wittgenstein's ideas that all categories are of a relative and diffuse nature have become heuristically important and, accordingly, a network of such connections is formed that have a center and a periphery. Moreover, the periphery contributes to filling the content of the categories with new meanings and the mutual penetration of the peripheral spheres of several categories also becomes an essential factor in the transformation of a single semantic field.

Socio-economic knowledge reflects the general cultural meaning of a particular society. This process is extremely complex and extended in time and space, gradually the use of specific things by a person in his activities displaces their immediate nature, that is, society is increasingly closed from direct perception of reality by the artificial environment, therefore, very often performing certain functions in an artificial environment, the created elements may have a different meaning in practical situations. As we see the issue of values, especially in a situation of the study of socio-economic processes, is absolutely justified. The concept of material value indicates the utility of the item and the possibility of its acquisition. In its turn, the nature of the meaning of value also changes: for the buyer it means the amount of donations necessary to purchase a product, and from the point of view of the seller it is power over the labor and products of others; also value can be a rule regulating exchange proportions, it can be as the amount of the 
purchased product of labor or it can be defined as the amount of products returned in exchange for the products given, value is also a perceived utility, that is, this is such a judgment of our thinking that gives things usefulness, thereby producing their value. The fundamental meaning of the concept of value lies in the emergence of the very idea of value and the fact that connects it with the process of exchange, when several people have agreed to exchange services, also value cannot coincide with the concept of utility and, as a rule, it is associated with quantitative characteristics and moments of complexity of the very production. It can be determined that the «value» of the economic sphere personifies itself as the unity of the utility of the good and the costs of its production. The nature of economic values demonstrates the possible ways and effectiveness of the results of human economic practice, the specificity of the forms of distribution, exchange, consumption of material goods, therefore «values and goals in the system of economic knowledge are, first of all, the structure of those values of human skills, abilities and economic events, which provides meaning to social experience and knowledge, indicates landmarks, samples, norms that determine the direction of the culture of the economic process»». They act as symbols or ideas that express and determine the orientation of people in the sphere of economic relations, within which practical actions of a production-material nature, tools and means of labor, manufactured products acquire meaning are understood and interpreted by people. Thanks to this mechanism the same «objective» knowledge and things constantly appear in the real experience of a person during his life, in the system of different values they acquire a different meaning.

The symbolic and artistic form of personification of the manifestation of economic life acquired the rank of ways of implementing the methods of comprehending reality already mastered during training, were built according to the laws and rules of composing a text, such various forms of it as grammar, rhetoric and poetics, on the one hand, and by the laws of logic as dialectics, relying on metaphysical principles and categories of thinking, on the other [2]. A separate area of manifestation of economic life in intellectual discourse is the creation of experimental and practical schemes of economic knowledge and it was essential that rational philosophical and economic views quite often created the context of political decisions and their argumentation, and the influence of many of those historical and 
political events should be taken into account, significantly slowed down the process of separating economic knowledge into a separate science. We cannot talk about material or ideal economic activity in society - social interaction requires additional characteristics for the study of social economic practice. If we study the economic system from the point of view of labor efficiency and other indicators of modern economic activity, then not only the socio-cultural meaning on which labor motivation is based is lost but mutual understanding between the acting subjects is lost. This methodological position concerns the current level of economic awareness, which means the means of economic analysis and scientific systems of quantitative characteristics.

The results of socio-economic knowledge arise in society as signs or symbols that record information, ideas and representations of people, a system of relationships, structure of states, frequency and nature of existence. So, in particular, economic knowledge creates opportunities for the reification of people's energy in the results of labor activity, therefore the concept of the structures of the life of an ethnos is preserved in the space of its economic existence in the form of economic and production material achievements and the texts of thinkers of the corresponding era, which are the main condition for the formation of its spiritual potential. Changes in economic and economic relations contributed to the acceleration of the development of scientific knowledge, required a further expansion of the education system, improved functioning of the sphere of international relations, as well as an appropriate philosophical understanding of the ways and forms of socio-economic development of society.

The existential relations of symbolic-economic structures, their subject field of signs and the place of the subject lies in the relationship between the rationalistic nature of epistemology and the tolerant attitude of the doctrine of signs regarding the opposite nature of concepts such as «objective» and «subjective», in fact, semantics at the deep level of symbolic and referential structures combines the principle of variability with a certain principle of limitation. The area of the relationship between socio-economic knowledge and the possibilities of its utterance is investigated, the complex relationship between the subject content of the utterance and its existential foundations is presented. The subject endowed with the abilities of a concrete historical interpreter of statements, loses the central position of the language indicated 
by the truth and the analysis itself shows a kind of double multiplication of semantic referents: first, those means of language are used that directly determine the things themselves; secondly, there is an appeal to the means of language artificially created on the basis of abstract regulators and both of these components of the analysis can neither coincide nor separate from each other.

\section{Knowledge as a linguistic dimension of reality based on subjective understanding}

Today theoretical and methodological approaches in the system of economic knowledge are characterized by a variety of scientific positions and sometimes they have opposite conclusions and practical recommendations that significantly limit the possibilities of their dialogue within the scientific environment. The economic knowledge of people can exist in various alternative forms. One of these alternatives is knowledge as a linguistic dimension of reality which is created on the basis of subjective understanding. In order to solve economic and issues a person must closely interact with other people. They must behave in such a way as to understand each other that is the form of such knowledge has an individualized character. The basis of this nature is formed by personal ideas, formed by the commitment of millions of people to certain principles and rules of economic activity. Modern activity in a competitive market, which today is regarded as a «knowledge machine», is fully consistent with the principle of induction which was once developed by $\mathrm{D}$. Hume. That is why the relevance of this research problem is further aggravated by the fact that overcoming the crisis state of the paradigm of any science, including economic, is practically impossible without the use of ideas and research mechanisms of the philosophy of science and epistemology in the system of cognitive activity. Modern economic methodology is showing an increased interest in the concepts and ideas of modern epistemology. This interest in time coincided with the post-positivist turn in the philosophy of science which was initiated by K. Popper, T. Kuhn, I. Lakatos and which ended with a complete rethinking of the meaning of epistemology in modern non-classical theories of knowledge. Trying to avoid the individualistic understanding of cognition, some of the positivist philosophers (L. Wittgenstein, B. Russell) tried to define cognition as a problem of the logical analysis of language 
and symbols. However, referring to the experience of analytical philosophy, this problem was not solved. The language itself, including the concept of «knowledge», has a polysemantic character, that is what was understood as knowledge, for example, in the $19^{\text {th }}$ century does not coincide with how it is interpreted today, especially if we take into account the existence of various trends in philosophy.

Existential philosophy on the contrary emphasizes the irrational nature of cognition, understanding it as an «existential enlightenment», an intuitive «implantation» into an object, an «experience» of the world, or as a form of human absurdity, which testifies to the incompatibility of emotionalsensory and logical-rational comprehension of things and the world [9]. In addition, science and education are interpreted by some existentialists as a form of ignorance organized by people, therefore they leave the question of defining the concept of knowledge open.

Thus, the most significant influence on the development of economic knowledge was carried out by the provisions of K. Popper's falsificationism and competing methodological concepts of rational reconstruction as a key to understanding the real history of I. Lakatos, ideas that appeared in the process of a rethought version of T. Kuhn's paradigmatic approach and other «non-classical» interpretations of science as a social construct but the topic of socio-epistemological analysis of modern economic knowledge is still open. Despite the fact that modern philosophical thought ambiguously defines the process of cognition, it generally recognizes the statement that cognition is a specific type of human activity which results in knowledge, that is, reliable information about the world in which people live. In addition to cognition other processes function in the spiritual life of society, testifying to the interests of people, their hopes and faith, the consideration and knowledge of which is important but goes beyond the philosophy of cognition.

Particular attention should be paid to the relationship between knowledge and expression and to establish a complex interdependence between the objective content of economic expression and its existential foundations. From the point of view of semantics, the subject of the corresponding systems studied by it is not given priority value, in contrast to analysis in classical epistemology where the main goal is to construct the doctrine of the universal logos or the formalism of human representations. It also differs from approaches in phenomenology when the extrapersonal 
acts of consciousness are investigated. As a result of the analysis it was found that the function of the subject extends from a specific or historical interpreter of the statement, which has lost the main position of the signified true language. In fact such an analysis multiplies the semantic referential representations or it uses such language means that are close enough to the things themselves and in parallel such linguistic means can be applied that were artificially created on the basis of abstract regulations and both approaches can either coincide or completely separate from each other.

Thus, the object of knowledge, in fact, is diffused between many positions so there can be no single position. A kind of interweaving of subjective acts with linguistic mechanisms takes place capturing ever new levels of determination operations in the absence of a single center of reference, as well as sufficiently significant gaps such as those that separate the speaking individual from the signifying logos and this approach does not at all aim at the procedure of scientific schematization.

Classical epistemology tries to approach the fundamental principles of the relationship of subjects to the world as a whole or to objects that differ in the world by means of cognitive acts. Modern structural philosophy is very closely associated with semantics and its approaches actually displaces the referential sphere of knowledge as an ontology of relations. From the very beginning it gives a detailed classification, in a certain way combining all normative instances and recognizes the action of the structuring function both in those languages with the help of which the connections of the situation of everyday experience are established, and those with the help of which objects are distributed in the space of knowledge. But such an arrogant unification narrows the space of knowledge that the linguistic types that have been united by this fundamental status, thereby change their characteristic features for example the sign of factuality or chance. Thus the subject of linguistic communication will himself find himself between these planes of existence: 1) being the subject of language, it acquires the status of a timeless correlator of definition; 2) being as the basis of the communication process, it becomes a participant in the fluid events of the language.

This approach provides a practical possibility of restructuring the relationship between the existential and formal relations of the statement in terms of semantics. The semantic nature of the relationship is determined by the objective correspondence between the sign and the signified and 
is built taking into account the preservation of distance in relation to subjectivity. But precisely because of this it embraces and uses subjectivity in a situation when it is necessary to turn again to the doctrine of meaning. There are fundamentally defined methodological foundations that do not allow scientific semantics to be a teaching about thinking. Such arguments are provided by extensional semantics, the subject of analysis of which are statements in the process of deployment of networks of correspondences, with the help of which the expression is connected with language, with the sphere of reference, with sociolinguistic contexts, no breaks in the network are allowed, and also in those cases when there is a need to find a place signifying the act or meaning. Pragmatic language learning follows exactly this rule of objectivity, it offers an expanded preferential system, in which, in addition to the rules, the position of listeners in space and time could be attracted. In this case, with all the positive provisions of the structural approach to language and the theory of interpretation, it leaves them as parts of a certain space of possible connections. The specified scientific requirement means only limitation of subjective factors and in no way a rejection of the ontology of their existence. In order to justify the conditional refusal of semantics from the subject, it would be necessary to admit that the circle of referential and communicative operations is closed on itself and without requiring external guarantees which again returned research to personal or historical existence.

If we assume possible theoretical means of overcoming such subjectivity, then the possible options may be as follows: the first means is a mechanical or behavioristic interpretation of speech operations; the second option is, on the contrary, the construction of such an interpretation on the basis of strict formal existence, which would not have any sources or correlations among concrete beings but only the terms of reference should be. In this case, we observe a convergence with both the nominalist approach, on the one hand, and the structuralist approach, on the other. The variant of the nominalistic path gives us quite the whole range of associations of signs with external stimuli, as well as the connection of signs with each other which are closed in their personal functioning without any connection with the subject. The variant of the structuralist path more fully overcomes temporal and genetic factors. Language is a system of coordination and transmission of information, one way or another, it dissolves in itself all the 
features associated with the presence of observers and listeners. Linguistic operations then take their definite place in the synchronous or timeless order of correlations, the law of which does not depend in any way on all the contingencies of the statement [10]. The subject is reduced to a certain space-time point of intersection, warning observation of the sequence of description and these feelings, he provides the communicative process with the material of expression, which becomes a message only after it is passed through the discursive schemes.

It is necessary to provide the indicated types of linguistic operations with the form of models but they are rather limited within the scope of semantic analysis. Real speech is much more than a collection of syntactic or semantic rules, it creates the environment where these rules appear or develop. In addition, the functions of the language, carried out in order to delimit the field of the indicated, correlate with other functions with the help of which the meaning is produced and reproduced in the contexts of communication, as well as the understanding of language as a code, which is superimposed on the material of information or statements, implicitly creates a prerequisite for structuring the entire semantic area. This situation is ambiguous because it covers up the relationship between the objects to which the signs belong and the practical and existential basis within which they are distinguished. When it comes to the style of a language, including a scientific one, then it is impossible not to correlate its statements with deductive or operational paradigms and it is also impossible to completely subordinate them to one or another metalanguage with the help of which control over these paradigms is carried out. It should be recalled that the use of language is the most theoretical act, which generates, respectively, its orientation and the corresponding set of metalanguages.

For the linguistic approach it embodies the process of studying the structures of specific languages, meaning or communicative value, acts as an implicit horizon of the statement or as an additional component of the organization of this structure. With the help of such reasoning we can argue about the priority of the existential features of the language over its formal features. It can be assumed that the assimilation of the code language implicitly occurs with the radical objectification of its semantics and with the interpretation of its autonomous mechanism, in fact, impersonal and timeless, thanks to which information is communicated and transmitted. 
The decision on which logical formalisms or mathematical symbols are based are additional means of clarification which by themselves cannot define the scientific language in its entirety.

So, in order to understand the practical inclusions of both natural and artificial languages, it is necessary to go beyond the coding rules and it is not necessary to abandon the stylistics of statements which reveals broader possibilities of symbolism and not just an orientation towards the signifier. Such symbolism performs a unifying function showing the subject's attitude to the world or interpreting his feelings. It should be noted that the reduction of symbols to coding is not an unambiguous moment, including the level of information languages. If we considered only pure complexes of signs that are controlled by logical syntax, the order of which exactly overlapped the order of the signifiers, then we would limit their possibilities. The point is that any formulas, including scientific ones, are always correlated with images and visual images, which allow, if not to provide a full meaning, then unambiguously call the meaning act and direct it in a certain way. So if we strive to fully cover all the possibilities of signs then it should be noted that the code manages uncoded layers, thanks to which a connection is established between speech and experience or that the code network leaves open opportunities for new potential thematizations, therefore the code does not lock on itself, but signified and is the entire linguistic organism.

Returning to the basics of the language we can argue that the use of any language including its restriction by the laws of syntax and vocabulary, is based on practice and symbolism, is not limited to any rules and turns out in linguistic innovations. Since the organization of a language is much older than its logical structure and goes beyond its limits, therefore, the study of semantic categories will remain the subject of archeology of the language and the analysis of the socio-historical conditions of its formation. Wittgenstein tries to outline the boundaries that are both primary and historical at the same time between what is only allowed by formulated knowledge and what is explained in it becomes in fact the subject of research. He notes that one might get the impression that there is something similar to the final analysis of our linguistic forms, respectively the only form of expression is completely disassembled into elements. That is, the impression is that our generally accepted forms of expression, in fact, have not yet been analyzed, as if they have something hidden that we need to discover. In 
turn, K. Popper has discursive approbation in the interval between critical facts and basic statements, which are themselves established not through evidence, but by virtue of some initial decisions or they are made without discussing the agreement.

We can call these provisions the fundamental foundations in order not to confuse the power of language with the dominance of code, language is not an intentionally established code, but when it is established, it allows a transition from pre-existing meanings to intentionally ordered meaning [9]. This property provides space for languages of cognition, when an exchange is carried out between the primary position or possession of signs and objectified by mechanisms. The directions of definition from the current situation with internal possibilities intersect with the transition from these latter to intuitive or practical sources of our statements. Epistemology defines the relationship between objectivity and subjectivity as an important category. The nature of such relations between them reminds us that nonrecognition of the subject as the basis of all perspectives is at the same time the destruction of what is related to it, that is, the world as the basis of knowledge. Instead of the subject, there remains a pure structure, a system of relationships that has no rootedness.

The subject endowed with the abilities of a concrete historical interpreter of statements, loses the central position of the language indicated by the truth and the analysis itself shows a kind of double multiplication of semantic referents: first, those means of language are used that directly determine the things themselves; secondly, there is an appeal to the means of language artificially created on the basis of abstract regulators and both of these components of the analysis can neither coincide nor separate from each other.

Today theoretical and methodological approaches in the system of economic knowledge are characterized by a variety of scientific positions and sometimes they have opposite conclusions and practical recommendations that significantly limit the possibilities of their dialogue within the scientific environment. The economic knowledge of people can exist in various alternative forms. One of these alternatives is knowledge as a linguistic dimension of reality, which is created on the basis of subjective understanding. In order to solve economic and issues a person must closely interact with other people. They must behave in such a way as to understand 
each other that is the form of such knowledge has an individualized character. The basis of this nature is formed by personal ideas, formed by the commitment of millions of people to certain principles and rules of economic activity. Modern activity in a competitive market, which today is regarded as a «knowledge machine», is fully consistent with the principle of induction, which was once developed by D. Hume. That is why the relevance of this research problem is further aggravated by the fact that overcoming the crisis state of the paradigm of any science, including economic, is practically impossible without the use of ideas and research mechanisms of the philosophy of science and epistemology in the system of cognitive activity. Modern economic methodology is showing an increased interest in the concepts and ideas of modern epistemology. This interest in time coincided with the post-positivist turn in the philosophy of science, which was initiated by K. Popper, T. Kuhn, I. Lakatos and which ended with a complete rethinking of the meaning of epistemology in modern non-classical theories of knowledge. Trying to avoid the individualistic understanding of cognition, some of the positivist philosophers (L. Wittgenstein, B. Russell) tried to define cognition as a problem of the logical analysis of language and symbols. However, referring to the experience of analytical philosophy, this problem was not solved. The language itself, including the concept of «knowledge», has a polysemantic character, that is, what was understood as knowledge, for example, in the 19th century does not coincide with how it is interpreted today, especially if we take into account the existence of various trends in philosophy.

Existential philosophy, on the contrary, emphasizes the irrational nature of cognition, understanding it as an «existential enlightenment», an intuitive «implantation» into an object, an «experience» of the world or as a form of human absurdity which testifies to the incompatibility of emotional-sensory and logical-rational comprehension of things and the world [9]. In addition, science and education are interpreted by some existentialists as a form of ignorance organized by people, therefore they leave the question of defining the concept of knowledge open.

Thus, the most significant influence on the development of economic knowledge was carried out by the provisions of K. Popper's falsificationism and competing methodological concepts of rational reconstruction as a key to understanding the real history of I. Lakatos, ideas that appeared in the 
process of a rethought version of T. Kuhn's paradigmatic approach and other «non-classical» interpretations of science as a social construct, but the topic of socio-epistemological analysis of modern economic knowledge is still open. Despite the fact that modern philosophical thought ambiguously defines the process of cognition, it generally recognizes the statement that cognition is a specific type of human activity, which results in knowledge, that is, reliable information about the world in which people live. In addition to cognition, other processes function in the spiritual life of society, testifying to the interests of people, their hopes and faith, the consideration and knowledge of which is important but goes beyond the philosophy of cognition.

Particular attention should be paid to the relationship between knowledge and expression and to establish a complex interdependence between the objective content of economic expression and its existential foundations. From the point of view of semantics the subject of the corresponding systems studied by it is not given priority value, in contrast to analysis in classical epistemology where the main goal is to construct the doctrine of the universal logos or the formalism of human representations. It also differs from approaches in phenomenology when the extrapersonal acts of consciousness are investigated. As a result of the analysis it was found that the function of the subject extends from a specific or historical interpreter of the statement, which has lost the main position of the signified true language. In fact, such an analysis multiplies the semantic referential representations or it uses such language means that are close enough to the things themselves and in parallel such linguistic means can be applied that were artificially created on the basis of abstract regulations and both approaches can either coincide or completely separate from each other.

Thus, the object of knowledge, in fact, is diffused between many positions so there can be no single position. A kind of interweaving of subjective acts with linguistic mechanisms takes place capturing ever new levels of determination operations in the absence of a single center of reference, as well as sufficiently significant gaps such as those that separate the speaking individual from the signifying logos and this approach does not at all aim at the procedure of scientific schematization.

Classical epistemology tries to approach the fundamental principles of the relationship of subjects to the world as a whole or to objects that differ in the world by means of cognitive acts. Modern structural philosophy is very 
closely associated with semantics and its approaches actually displaces the referential sphere of knowledge as an ontology of relations. From the very beginning it gives a detailed classification, in a certain way combining all normative instances and recognizes the action of the structuring function both in those languages with the help of which the connections of the situation of everyday experience are established and those with the help of which objects are distributed in the space of knowledge. But such an arrogant unification narrows the space of knowledge that the linguistic types that have been united by this fundamental status, thereby change their characteristic features, for example, the sign of factuality or chance. Thus, the subject of linguistic communication will himself find himself between these planes of existence: 1) being the subject of language it acquires the status of a timeless correlator of definition; 2) being as the basis of the communication process it becomes a participant in the fluid events of the language.

This approach provides a practical possibility of restructuring the relationship between the existential and formal relations of the statement in terms of semantics. The semantic nature of the relationship is determined by the objective correspondence between the sign and the signified and is built taking into account the preservation of distance in relation to subjectivity. But precisely because of this, it embraces and uses subjectivity in a situation when it is necessary to turn again to the doctrine of meaning. There are fundamentally defined methodological foundations that do not allow scientific semantics to be a teaching about thinking. Such arguments are provided by extensional semantics, the subject of analysis of which are statements in the process of deployment of networks of correspondences, with the help of which the expression is connected with language, with the sphere of reference, with sociolinguistic contexts, no breaks in the network are allowed, and also in those cases when there is a need to find a place signifying the act or meaning. Pragmatic language learning follows exactly this rule of objectivity, it offers an expanded preferential system, in which, in addition to the rules, the position of listeners in space and time could be attracted. In this case, with all the positive provisions of the structural approach to language and the theory of interpretation, it leaves them as parts of a certain space of possible connections. The specified scientific requirement means only limitation of subjective factors and in no way a rejection of the ontology of their existence. In order to justify the conditional 
refusal of semantics from the subject, it would be necessary to admit that the circle of referential and communicative operations is closed on itself, and without requiring external guarantees, which again returned research to personal or historical existence.

If we assume possible theoretical means of overcoming such subjectivity, then the possible options may be as follows: the first means is a mechanical or behavioristic interpretation of speech operations; the second option is, on the contrary, the construction of such an interpretation on the basis of strict formal existence, which would not have any sources or correlations among concrete beings but only the terms of reference should be. In this case, we observe a convergence with both the nominalist approach, on the one hand, and the structuralist approach, on the other. The variant of the nominalistic path gives us quite the whole range of associations of signs with external stimuli, as well as the connection of signs with each other, which are closed in their personal functioning, without any connection with the subject. The variant of the structuralist path more fully overcomes temporal and genetic factors. Language is a system of coordination and transmission of information, one way or another, it dissolves in itself all the features associated with the presence of observers and listeners. Linguistic operations then take their definite place in the synchronous or timeless order of correlations, the law of which does not depend in any way on all the contingencies of the statement [10]. The subject is reduced to a certain space-time point of intersection, warning observation of the sequence of description and these feelings, he provides the communicative process with the material of expression, which becomes a message only after it is passed through the discursive schemes.

It is necessary to provide the indicated types of linguistic operations with the form of models, but they are rather limited within the scope of semantic analysis. Real speech is much more than a collection of syntactic or semantic rules, it creates the environment where these rules appear or develop. In addition, the functions of the language, carried out in order to delimit the field of the indicated, correlate with other functions with the help of which the meaning is produced and reproduced in the contexts of communication, as well as the understanding of language as a code, which is superimposed on the material of information or statements, implicitly creates a prerequisite for structuring the entire semantic area. This situation 
is ambiguous because it covers up the relationship between the objects to which the signs belong and the practical and existential basis within which they are distinguished. When it comes to the style of a language, including a scientific one, then it is impossible not to correlate its statements with deductive or operational paradigms and it is also impossible to completely subordinate them to one or another metalanguage with the help of which control over these paradigms is carried out. It should be recalled that the use of language is the most theoretical act, which generates, respectively, its orientation and the corresponding set of metalanguages.

For the linguistic approach it embodies the process of studying the structures of specific languages, meaning or communicative value, acts as an implicit horizon of the statement or as an additional component of the organization of this structure. With the help of such reasoning we can argue about the priority of the existential features of the language over its formal features. It can be assumed that the assimilation of the code language implicitly occurs with the radical objectification of its semantics and with the interpretation of its autonomous mechanism, in fact, impersonal and timeless, thanks to which information is communicated and transmitted. The decision on which logical formalisms or mathematical symbols are based are additional means of clarification, which by themselves cannot define the scientific language in its entirety.

So in order to understand the practical inclusions of both natural and artificial languages, it is necessary to go beyond the coding rules and it is not necessary to abandon the stylistics of statements which reveals broader possibilities of symbolism and not just an orientation towards the signifier. Such symbolism performs a unifying function showing the subject's attitude to the world or interpreting his feelings. It should be noted that the reduction of symbols to coding is not an unambiguous moment, including the level of information languages. If we considered only pure complexes of signs that are controlled by logical syntax, the order of which exactly overlapped the order of the signifiers, then we would limit their possibilities. The point is that any formulas, including scientific ones, are always correlated with images and visual images, which allow, if not to provide a full meaning, then unambiguously call the meaning act and direct it in a certain way. So if we strive to fully cover all the possibilities of signs then it should be noted that the code manages uncoded layers, thanks to which a connection is 
established between speech and experience or that the code network leaves open opportunities for new potential thematizations, therefore the code does not lock on itself, but signified and is the entire linguistic organism.

Returning to the basics of the language, we can argue that the use of any language, including its restriction by the laws of syntax and vocabulary, is based on practice and symbolism, is not limited to any rules and turns out in linguistic innovations. Since the organization of a language is much older than its logical structure and goes beyond its limits, therefore, the study of semantic categories will remain the subject of archeology of the language and the analysis of the socio-historical conditions of its formation. Wittgenstein tries to outline the boundaries that are both primary and historical at the same time, between what is only allowed by formulated knowledge and what is explained in it becomes in fact the subject of research. He notes that one might get the impression that there is something similar to the final analysis of our linguistic forms, respectively the only form of expression is completely disassembled into elements. That is, the impression is that our generally accepted forms of expression, in fact, have not yet been analyzed, as if they have something hidden that we need to discover. In turn, K. Popper has discursive approbation in the interval between critical facts and basic statements, which are themselves established not through evidence, but by virtue of some initial decisions or they are made without discussing the agreement.

We can call these provisions the fundamental foundations in order not to confuse the power of language with the dominance of code, language is not an intentionally established code, but when it is established, it allows a transition from pre-existing meanings to intentionally ordered meaning [9]. This property provides space for languages of cognition, when an exchange is carried out between the primary position or possession of signs and objectified by mechanisms. The directions of definition from the current situation with internal possibilities intersect with the transition from these latter to intuitive or practical sources of our statements. Epistemology defines the relationship between objectivity and subjectivity as an important category. The nature of such relations between them reminds us that nonrecognition of the subject as the basis of all perspectives is at the same time the destruction of what is related to it, that is, the world as the basis of knowledge. Instead of the subject, there remains a pure structure, a system of relationships that has no rootedness. 
Epistemology constantly borders between these poles of existence, thus requiring the «help» of semantics, which differentiates the modalities of a given relationship, streamlines the structural plans and moments of actualization of a certain, while accepting the help of history, places the terms of this relationship in a specific field of their disagreements. A person is partially included in the models, thanks to which his attitude to the world around him is formed, but at the same time he remains signified, and the birth of the same models then depends on him.

So the object of socio-economic knowledge is diffused between many positions and cannot get the meaning of a single whole. The subject of linguistic communication himself finds himself between double layers: on the one hand, relying on experience or communication, he becomes a participant in the unstable and temporary events of the language; on the other hand, as a subject of language, he will be a timeless correlator of definition - such an approach provides a practical possibility of restructuring the relationship between existential and formal conditions of statements, provides a transition to the foundations of the modern existentialanthropological tradition.

\section{Conclusions}

Language does not reflect the meaning of things and processes of a certain field of activity, but reveals their content and attaches importance within the framework of practical activities of a production-material nature. It is the words that are translated into the subconscious, and then into the conscious meaning of things, which is depicted in the mentality of each nation. The study of the genetics of the application of economic and economic concepts in a certain historical territory, the formation of a semiotic space of socioeconomic culture and the procedure for recognizing its word-signs builds a system for understanding the economic mentality in intellectual discourse.

The dynamics of the information process in the context of a postindustrial society is determined by such important approaches as world transformational changes, represented by a single social process, which is determined by revolutionary technological transformations in the modern world economy, as well as the specificity of its own paradigm of the national semantic field and the type of production and economic culture. The interaction of these parties is associated with the adaptation of the economic 
and technological structures of civilization to the spiritual and cultural specifics of the existence of a specific ethnic community. The mentioned components are united by the process of dynamic development of cultural and communication technologies, which bring significant changes to the nature of modern civilizational relations. In turn, the specific production component is associated with spiritual and cultural principles, which in this context are based on the internal economic and economic content of ancient written literary sources belonging to the spiritual heritage, starting with the consideration of hermeneutic features [7] and the influence of political events. We focus on the activity sense of the language and the linguistic foundations of sociocultural knowledge of economic reality. The solution of the tasks posed requires the use of the autochthonous principle of clarifying the special historical and cultural experience, language and specific principles and means of economic and economic life support of a particular people with permanent residence in a certain territory. The architectonics of socio-economic knowledge is a historically established structure of those values, human skills, abilities and socio-economic events, which provides meaning to social experience and knowledge, indicates landmarks, patterns, norms that form the cultural specifics of the national economic process. They act as symbols and ideas that express and determine the orientation of people in the sphere of economic relations, within which the practice of a production and economic nature and the results of such work acquire meaning, are analyzed by people thanks to cognitive communicative and linguistic practices. As a result, the objective nature of the correspondence between knowledge and things, which constantly fill the real experience of a person throughout life, acquires mismatched meanings in various value coordinates. An integral synthetic unity is being formed in a complex model of «dialogical» methodology, which includes the uncertainty and plurality of reference systems, thereby ensuring the transition from the abstractepistemological to the modern existential-anthropological tradition, respectively, the analysis of the nature of the internal harmonization of the language and socio-economic reality.

This approach substantiates the analysis of the mechanism of interaction between the systemic nature of material production and world economic processes with the national paradigm of economic knowledge, which ensures the formation of their own mental and semantic field of economic 
and production activities of people. Since the organization of a language is much older than its logical structure and goes beyond its limits, therefore, the study of semantic categories will remain the subject of archeology of the language and the analysis of the socio-historical conditions of its formation.

\section{References:}

1. Apel K.-O. (1997) Transtsendentalno-hermenevticheskoye ponyatiye yazyka [Transcendentally-hermeneutic concept of language]. Questions of philosophy, no. 1, pp. 76-92.

2. Beilin M.V. (2014) Tekhnicheskiye artefakty v yazykovoy kartine mira [Technical artifacts in the language picture of the world]. Yearbook of Eastern European Studies, no. 4, pp. 17-26.

3. Benvenist E. (1974) Obshchaya lingvistika [General linguistics trans. from French]. Moscow: Progress. (in Russian)

4. Berger P. (1995) Sotsialnoye konnstruirovaniye realnosti: Traktat po sotsiologiyi znaniya [Social construction of reality: A treatise on the sociology of knowledge]. Moscow. (in Russian)

5. Bodriyar Zh. (2003) K kritike politicheskoy ekonomiyi znaka [To the criticism of the political economy of the sign], Moscow: Biblion-Russian book. (in Russian)

6. Brodel F. (1997) Materialna tsyvilizatsiya, ekonomika $i$ kapitalizm, $X V-X V I I I$ st. [Material civilization, economics and capitalism, XV-XVIII centuries]. Kyiv: Osnovi. (in Ukrainian)

7. Gadamer H.-G. (1988) Istina i pravda. Opyt filosofskoy germenevtiki [Truth and Method. Experience of Philosophical Hermeneutics]. Moscow: Progress. (in Russian)

8. Gumboldt fon V. (2000) O razlichiyi stroyeniya chelovecheskih yazykov i yego vliyanii na duhovnoye razvitiye chelovechestva [On the difference in the structure of human languages and its influence on the spiritual development of mankind]. Izbrannyye trudy po yazykoznaniyu [Selected works on linguistics]. Moscow: Progress, pp. 37-298. (in Russian)

9. Gusserl E. (2000) Logicheskiye issledovaniya. Kartezianskiye razmyshleniya. Krizis evropeyskih nauk $i$ transtsedentalnaya fenomenologiya. Filosofiya kak strogaya nauka [Logical research. Cartesian Reflections. The crisis of European sciences and transcendental phenomenology. Philosophy as a rigorous science]. Minsk: Harvest, Moscow: AST. (in Russian)

10. Homskiy N. (1972) Yazyk i myshleniye [Language and thinking]. Moscow: Izdatelstvo Moskovskogo universiteta. (in Russian)

11. Laclau E., Mouffe C. (1990) Post-Marxism without apologie. London: Verso.

12. Mak-Klosky D. (2004) Ritorika. Ekonomicheskaya teoriya [Rhetoric. Economic theory]. Moscow. (in Russian)

13. Marx K. (1960) Ekonomicheskiye rukopisi 1857-1859 [Economic manuscripts 1857-1859]. Moscow: Gospolitizdat, vol. 12, pp. 709-741. (in Russian) 
14. Merton R.K. (2006) Sotsialnaya teoriya i sotsialnaya struktura [Social theory and social structure]. Moscow: AST. (in Russian)

15. Parsons T. (1998) Sistema sovremennyh obshchestv [System of modern societies]. Moscow: Aspent Press. (in Russian)

16. Postmodernism. Ensyklopediya [Postmodernism. Encyclopedia]. Minsk: Interpressservice; Kn. Dom. 2001. (in Russian)

17. Veber M. (1990) Izbrannyye proizvedeniya [Selected Works]. Moscow: Progress. (in Russian)

18. Vitgenshtein L. (1994) Filosofskiye issledovaniya [Philosophical studies]. P. 1. Moscow: Gnosis. (in Russian) 